\title{
MAPA DE FALLAS DE LOS VOLCANES CHILES-CERRO NEGRO (NARIÑO) A PARTIR DE MINERÍA DE DATOS Y CONFIRMACIÓN DE CAMPO
}

\author{
Laura C. Bocanegra ${ }^{1 *}$; John J. Sánchez ${ }^{2}$
}

DOI: http://dx.doi.org/10.18273/revbol.v39n3-2017005 @ (1)

Forma de citar: Bocanegra, L.C., y Sánchez, J.J. 2017. Mapa de fallas de los volcanes Chiles-Cerro Negro (Nariño) a partir de minería de datos y confirmación de campo. Boletín de Geología, 39(3): 71-86.

\section{RESUMEN}

Se realizó la compilación de un mapa de fallas y lineamientos en la región de interés del proyecto binacional geotérmico Tufiño-Chiles-Cerro Negro en la frontera colombo-ecuatoriana. El mapa se construyó mediante minería de datos consultando todas las fuentes de información publicadas y disponibles que incluyen trazos de fallas y lineamientos. Se descartaron las estructuras que presentaron repetición entre fuentes teniendo en cuenta la georreferenciación resultante de los diferentes mapas publicados. Adicionalmente se proponen nuevos lineamientos con base en la inspección visual de un modelo de elevación digital (DEM) con resolución de $30 \mathrm{~m}$, e imágenes satelitales LANDSAT con resolución de $15 \mathrm{~m}$. De la literatura se extrajeron un total de 30 lineamientos, mientras que la inspección visual del DEM reveló 50 potenciales lineamientos. En total 14 lineamientos cruzan el área de interés del proyecto binacional geotérmico, presentando dos tendencias en orientación: SE-NW (sistema transversal) y SW-NE (sistema longitudinal), con una clara predominancia del sistema transversal. El presente estudio reviste importancia en la localización de lineamientos controladores de la circulación de fluidos geotérmicos.

Palabras clave: Geotermia; Volcanes Chiles - Cerro Negro; Proyecto geotérmico binacional Colombia Ecuador; lineamientos; fluidos geotérmicos.

\section{MAP OF FAULTS FOR THE CHILES - CERRO NEGRO VOLCANOES REGION (NARIÑO) FROM DATA MINING AND FIELD CONFIRMATION}

\begin{abstract}
A compilation of faults and lineaments within the region of interest of the Binational Geothermal Project TufiñoChiles-Cerro Negro (Colombia-Ecuador border) was achieved by means of data mining among all available published sources of information, which included fault traces and lineaments. Examination and georeferencing of features included in the various sources of information allowed discarding repeated structures. A number of new potential lineaments are proposed based on visual inspection of a 30-m resolution DEM and a $15-\mathrm{m}$ resolution LANDSAT image. A total of 30 potential lineaments were found in the literature, 50 additional lineaments were inferred from images analyses and 14 lineaments were found which include segments that cross the interest area of the geothermal project. The latter are oriented SE-NW (transversal system) and SW-NE (longitudinal system), with dominance of the transversal system. The present study highlights the importance of lineaments and faults on the controls on geothermal fluids circulation.
\end{abstract}

Keywords: Geothermal Energy; Chiles - Cerro Negro volcanoes; Binational Geothermal Project Colombia Ecuador; lineaments; geothermal fluids.

\footnotetext{
${ }^{1}$ Departamento de Geociencias, Universidad Nacional de Colombia, Bogotá, Cundinamarca, Colombia. (*)lcbocanegrar@unal.edu.co

${ }^{2}$ Departamento de Geociencias y Medio Ambiente, Universidad Nacional de Colombia, Medellín, Antioquia, Colombia. jjsanchezag@unal.edu.co
} 


\section{INTRODUCCIÓN}

En Colombia se han adelantado estudios de geotermia en varias zonas del país, por ejemplo: Volcán Nevado del Ruiz, Paipa-Iza, y Volcán Azufral. En las investigaciones han participado entidades como el Servicio Geológico Colombiano (Alfaro et al., 2015), empresas como ISAGEN (Marzolf, 2014) y universidades como la Universidad Nacional de Colombia (Ayala, 2014; Coronado, 2014; Prieto, 2006; Moyano, 2015). Este trabajo se enfoca en el estudio de estructuras (fallas, lineamientos) en el área de interés denominado Proyecto Geotérmico Binacional (PGB), que incluye los volcanes Chiles-Cerro Negro, ubicados en la Cordillera Occidental en límites con Ecuador.

La energía geotérmica tiene su fuente en el flujo de calor interno de la Tierra y uno de los principales propósitos de la investigación en geotérmia es la definición de un modelo geológico conceptual del sistema (INGEOMINAS, 2009) que incluya información sobre la fuente de calor, la naturaleza del fluido geotérmico y el reservorio (por ejemplo: delimitación de las capas permeables e impermeables), y la localización de las áreas de recarga y descarga (modelo hidrológico e hidrogeológico; Marzolf, 2014). Eventualmente un modelo conceptual es insumo importante en lo referente al potencial aprovechamiento de la energía en usos directos e indirectos (piscinas termales, calefacción, generación de energía, entre otros).

La finalidad de este trabajo es la construcción de un mapa de fallas para el área general de interés que incluye los volcanes Chiles-Cerro Negro de Mayasquer, que sirva como insumo en el refinamiento de un modelo conceptual cuya definición está en progreso (García, 2016).

\section{Marco geológico}

Los volcanes Chiles - Cerro Negro de Mayasquer se localizan en la Cordillera Occidental al suroccidente de Colombia (FIGURA 1). El área de estudio incluye paisajes volcánicos, glaciares y denudacionales y como rasgos geomorfologicos importantes se tienen los edificios volcánicos de Azufral, Cumbal, Chiles y Cerro Negro Mayasquer, entre otros. Estos volcanes presentaron actividad desde el Mioceno tardío hasta el Holoceno, con depósitos piroclásticos recientes recubriendo la cordillera y el altiplano nariñense (Velásquez y Parra, 2002).

La evolución geológica del área comienza desde el Cretácico tardío, específicamente en el Campaniano (Jaillard et al., 2004), con la formación de un piso oceánico; representado por los Grupos Diabásico y Dagua (Velásquez y Parra, 2002). Posteriormente un cambio en el movimiento de la Placa Caribe generó acreción oblicua con respecto al margen norte de Suramérica ocasionando el levantamiento y posterior erosión de la Cordillera Central (Acosta et al., 2007). Autores como Duncan y Hargraves (1984) proponen una reorientación en el movimiento de las placas Suramericana, Caribe y Farallón, donde el fraccionamiento de esta última, generó las microplacas Cocos y Nazca, dando inicio al evento de orogenia andina.

Bayona et al. (2012) proponen que desde el Cretácico tardío ocurrieron eventos de subducción y actividad magmática, reposo en el Paleógeno temprano, y posterior reactivación del magmatismo en el Mioceno debido a la subducción de la placa de Nazca.

Nuevamente, en el Pleistoceno inferior la actividad magmática disminuyó hasta su reactivación en el Pleistoceno superior con la formación de los edificios volcánicos Caguil, Cerro Crespo-Nasate y Cerro Colorado. Esta actividad se prolongó aproximadamente 200.000 años, tiempo durante el cual se formaron nuevos edificios como los de los volcanes Chiles y Cerro Negro de Mayasquer con etapas de erupciones volcánicas y efusiones, siguiendo en esta actividad hasta hace 15.000 años, cuando el volcán Chiles se encontraba en las últimas etapas de su actividad efusiva, mientras Cerro Negro exhibió actividad eruptiva aproximadamente hace 6.200 años (Velásquez y Parra, 2002).

\section{Geología estructural}

La zona presenta un estilo estructural complejo con un fuerte plegamiento tipo chevron con una vergencia hacia el W, principalmente en las unidades Cretácicas, mientras que en lo referente a las fallas la tendencia regional muestra una dirección preferencial N20E. A continuación, se mencionan los rasgos principales de las fallas documentadas en el área de interés. La mayoría de datos provienen de Perdomo et al. (1986), aunque se mencionan referencias adicionales según sea el caso.

Falla Guachucal: Presenta un carácter transcurrente, con desplazamiento dextro-lateral. Las direcciones de los planos de fallas asociados varían entre N55E/35NW, N20E/45SE y N55W/80SW (Pachón, 2006).

Falla Chiles-Cumbal: Lineamiento topográfico a través del área del volcán Chiles y el lado E del cráter del volcán Nasate, prolongándose hacia el Ecuador. Hay evidencias de fuentes termales en la Quebrada Río Blanco, aledaña a este lineamiento. Se considera una continuación de la Falla Cauca-Patía. 


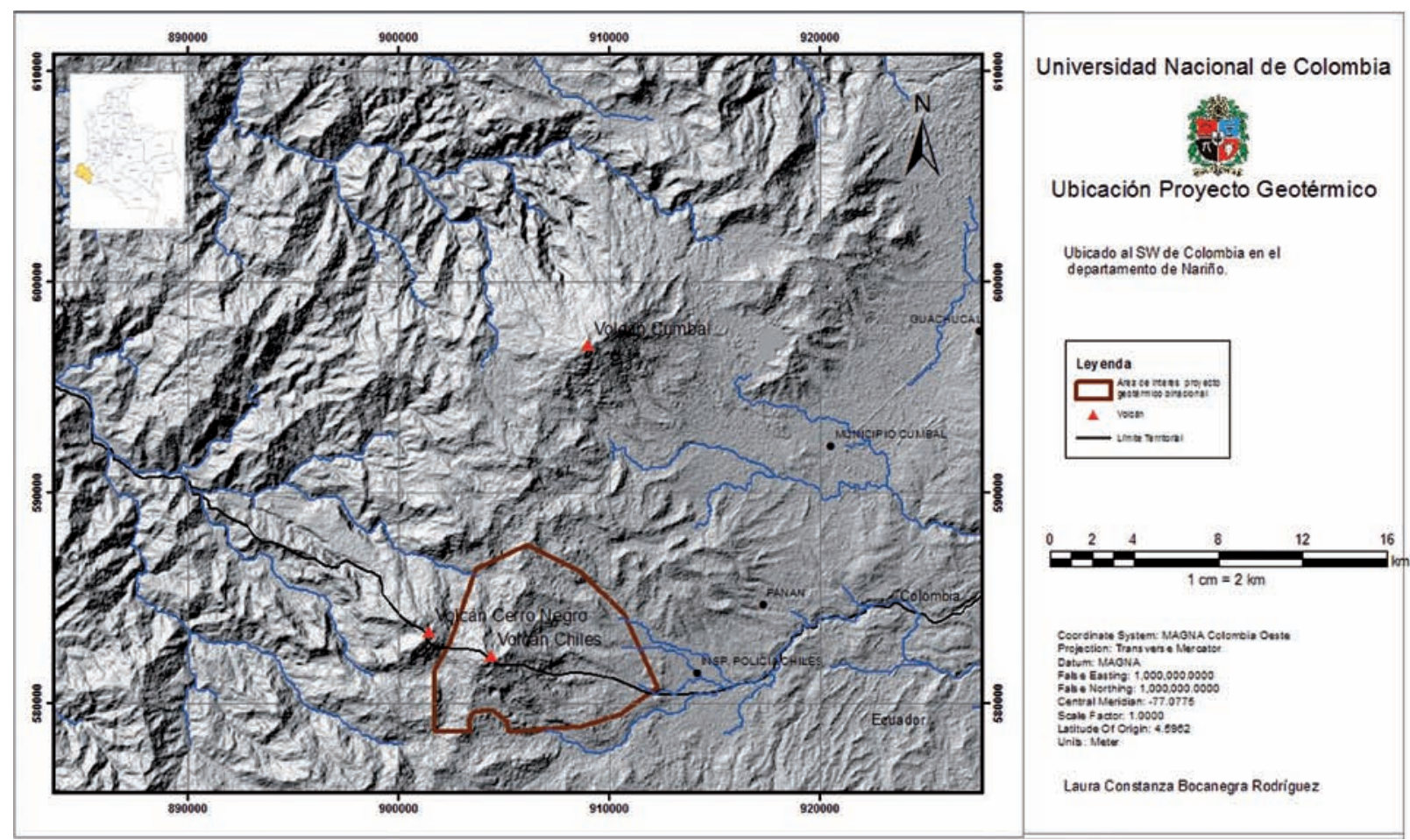

FIGURA 1. Localización del área de estudio. El polígono de color marrón delimita el área aproximada del PGB.

Falla Chiles-Norte: Su traza recorre el sector N del área de interés del PGB (FIGURA 1), es una falla transversal que sigue el cauce del Río Mayasquer hacia el W.

Falla Chiles-Cerro Negro: Falla transversal que pasa por los cráteres de los dos volcanes del área de estudio. Probablemente sigue el cauce del Río Chilma hacia el W y por el E se asocia a las fuentes termales del sector "Aguas Hediondas" en Ecuador.

Falla Cerro Negro-Nasate: Presenta una dirección NE, atravesando los volcanes Cerro Negro y Nasate. La identificación de esta falla se basó en lineamientos topográficos y la existencia de una zona muy fracturada en el borde sur del cráter del volcán Cerro Negro.

Falla Tufiño: Se prolonga desde Ecuador y marginalmente cruza el área de interés del PGB (FIGURA 1), presenta una dirección N30E. La identificación de esta falla (Perdomo et al., 1986) se fundamentó en la existencia, tanto de volcanes alineados en igual dirección en el Ecuador, como de cambios topográficos abruptos.

Falla Nasate: Presenta una dirección NW-SE y afecta el volcán Nasate.

\section{METODOLOGÍA}

La construcción del mapa de fallas se llevó a cabo en cuatro fases, descritas a continuación.

\section{Recopilación bibliográfica}

Comprendió la revisión detallada de documentos con información relacionada al área de interés. El principal propósito de la búsqueda de este material fue la identificación de las fallas en la zona que fueron documentadas en publicaciones. Adicionalmente, se realizó una búsqueda de literatura a nivel regional, incluyendo artículos con énfasis en la región sur occidental de Colombia. Se localizaron reportes y publicaciones de múltiples investigaciones y las principales fuentes disponibles incluyeron los trabajos de Velásquez y Parra (2002), Perdomo et al. (1986), Pinilla et al. (2007), Paris et al. (2000), Bayona et al. (2012), Jaillard et al. (2004), Acosta et al. (2007) y Rodríguez et al. (2008). Durante esta fase se realizó la digitalización de fallas y lineamientos reportados en los mapas de diferentes publicaciones usando software GIS (ArcGis) con el fin de construir un único mapa previo a la fase de campo. Este mapa fue denominado el mapa de referencias bibliográficas. 


\section{Análisis e interpretación de imágenes satelitales}

Las imágenes interpretadas durante esta fase fueron obtenidas de Earth Explorer (USGS, 2016). Se utilizó un modelo digital de elevación (DEM) y adicionalmente imágenes LANDSAT ETM+. Ambos tipos de datos fueron debidamente procesados mediante ArcGis. Específicamente, en el análisis del modelo digital DEM se optó por el uso de las herramientas de generación denominadas Hillshade para caracterizar mediante cambios en escalas de grises las variaciones en el relieve del área y realizar la identificación de lineamientos. El cambio sistemático en ángulo de iluminación permitió corroborar o descartar estructuras lineales. La herramienta TIN (Triangular Irregular Networks), permitió la detección de cambios topográficos para su posterior verificación en campo. Otras herramientas utilizadas fueron el mapa de pendientes (para determinar lineamientos) y el mapa de orientación de laderas. Para el estudio de los lineamientos en imágenes LANDSAT se usó la banda compuesta 742, una combinación en falso color con la cual se puede reconocer e interpretar el estilo estructural de la zona. Por último, se complementó con el uso de fotografías aéreas del período 1984-1995 en las cuales los cambios en escalas de grises pueden representar lineamientos principales. En la TABLA 1 se relacionan los datos relevantes de los grupos de fotos utilizados. Al mapa resultante del análisis de las imágenes mencionadas se le denominó mapa de imágenes satelitales.

TABLA 1. Conjuntos de fotos aéreas usadas para complementar el estudio de lineamientos en el área de interés.

\begin{tabular}{cccc}
\hline \multicolumn{1}{c}{ Vuelo } & Año & Escala & Fotografías \\
\hline C 1984-19-81 S-30650 & 1984 & $*$ & $36-31$ \\
C 2245-25-86 S-33451 & 1984 & $1: 25540$ & $253-234$ y 256-259 \\
C 2468-14-91 S-36232 & 1991 & $1: 14400$ & $107-136$ \\
C 2517-36-93 S-36741 & 1993 & $1: 36600$ & $105-120$ \\
C 2517-34-95 S-3642 & 1995 & $1: 34500$ & $121-135$ \\
\hline
\end{tabular}

* Información no disponible en las fotos.

\section{Trabajo de campo}

Los autores realizaron una salida de campo de cuatro días, durante la cual se materializó el reconocimiento de la zona y la recopilación de datos litológicos y estructurales. La toma de datos estructurales se enfocó en afloramientos de carretera en vías que recorren el área de los volcanes Chiles y Cerro Negro de Mayasquer en sentido general E-W, a lo largo de los flancos norte y sur, partiendo desde la población de Tufiño (Ecuador) y desde el corregimiento de Chiles (Colombia). Los datos recolectados incluyeron acimut y buzamiento de diaclasas y fracturas, así como estimados de densidad de discontinuidades (fallas, diaclasas, fracturas) a lo largo de una distancia de $1 \mathrm{~m}$ en afloramientos de corte de carretera y distancias entre 10 a 20 metros en afloramientos de difícil acceso para la aplicación del método RMR (Rock Mass Rating System) (Jerram y Petford, 2011).

\section{Análisis y comparación de datos teóricos y de campo}

En esta etapa se unificaron los datos obtenidos en campo con la información de una campaña adicional realizada en 2015 (García, 2016). En total se compilaron datos de treinta estaciones y se compararon con los mapas de referencias y de imágenes satelitales, con el fin de crear un mapa final de fallas y lineamientos en la región de los volcanes Chiles-Cerro Negro. Por último, a los datos obtenidos en cinco de las estaciones de campo se aplicó el método RMR, para la clasificación geomecánica de la roca mediante la determinación del esfuerzo compresivo y el carácter cualitativo de sus propiedades físicas. El análisis RMR involucró dos etapas:

Etapa 1. Recolección de datos: Medición directa o indirecta (mediante el uso de fotografías de alta resolución, en condiciones de difícil acceso) el espaciamiento entre las discontinuidades (fallas, fracturas o diaclasas) presentes en la roca a lo largo de líneas de referencia (transversal a las discontinuidades) con longitud de $1 \mathrm{~m}$ en afloramiento y hasta $20 \mathrm{~m}$ en fotografías. Las observaciones de interés en las diferentes discontinuidades fueron la orientación, el ancho, la naturaleza abierta o cerrada, el tipo de relleno y se reportó cualquier otro rasgo de interés. Las rocas (que corresponden a las lavas andesíticas del Chiles (Q1ach1, Q1ach3) y flujos de escombros del Chiles (Q1fech) (Velásquez y Parra, 2002), presentaban moderada meteorización, así como diaclasamiento y fracturamiento de carácter variable en dimensiones e intensidad. De igual manera, se observó variabilidad en el relleno de las discontinuidades: algunas fracturas presentaban alteración hidrotermal de color verde, mientras que otras estaban rellenas por material fino (limo o arcilla) con colores que variaban de amarillo a verde pálido, posiblemente de origen hidrotermal. Los materiales más finos cerca de las discontinuidades se identificaron como roca triturada y harina de falla. La FIGURA 2 muestra ejemplos de tres afloramientos característicos y el lector es referido a la TABLA 2 para detalles acerca de todas las estaciones de las dos campañas de campo. 

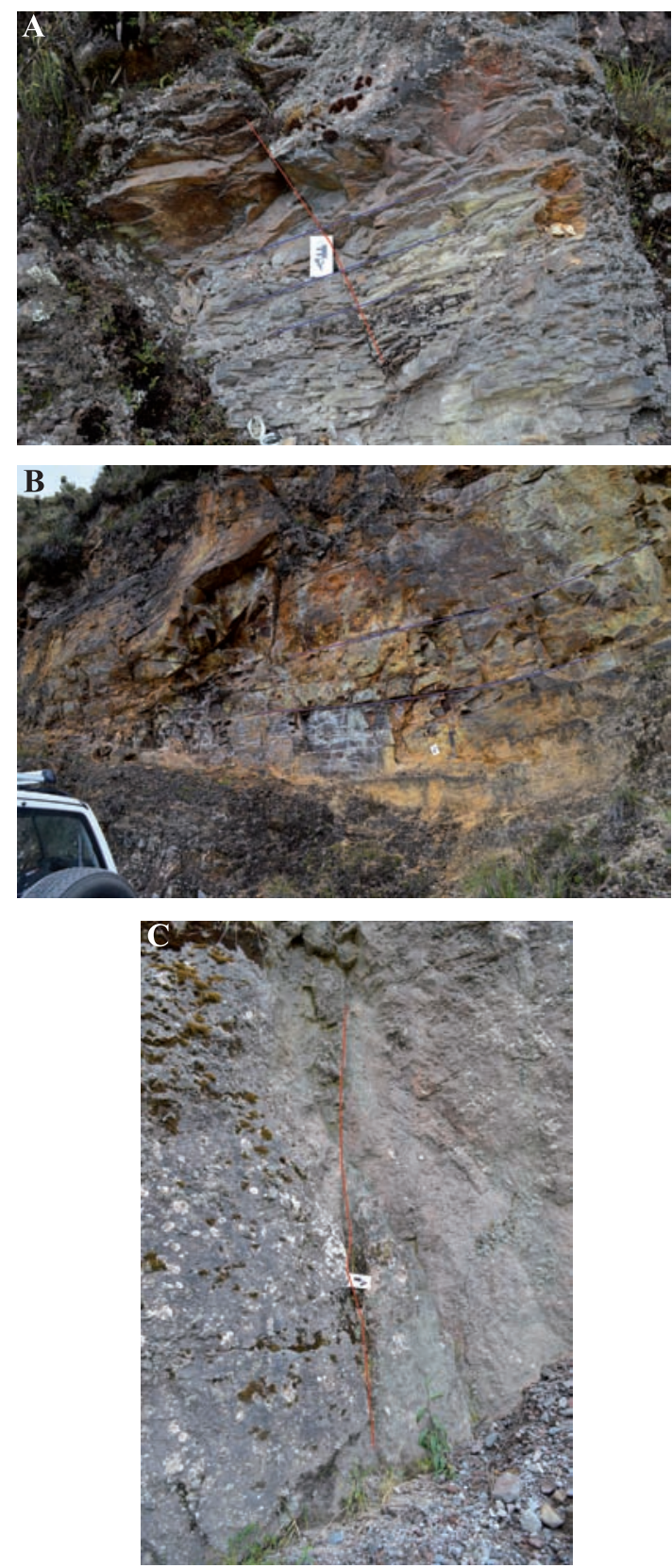

FIGURA 2. Fotografías de afloramientos carcaterísticos del área de estudio, donde se aprecian las diferentes discontinuidades documentadas. A. Afloramiento LCBR-06. Lavas andesíticas con textura porfirítica (lavas andesíticas del Chiles), se observan dos rasgos: fractura de longitud métrica (línea roja) y diaclasas de enfriamiento cuasi ortogonales a la fractura (líneas azules). El Norte apunta saliendo de la foto. B. Afloramiento LCBR-10. Corte de carretera en la vía Cristo Rey, lava andesítica (lavas andesíticas del Chiles) fuertemente meteorizada con color café (oxidación), se observan diaclasas de enfriamiento (líneas azules) con inclinación leve. La dirección Norte hacia la parte superior de la foto. C. Afloramiento LCBR-14. Cantera en la vía Tufiño-Maldonado, lava porfirítica de composición andesítica, se observan texturas de brecha y fracturas rellenas de material posiblemente de origen hidrotermal (línea roja). La dirección Norte apunta hacia la derecha. Fotografías: Laura C. Bocanegra.
Etapa 2. Estimación de esfuerzo en roca usando el criterio Hoek-Brown: Se realizaron cálculos para calcular de modo aproximado el esfuerzo de compresión en la roca para posterior implementación en la clasificación RMR. En la clasificación de la roca, se tuvieron en cuenta los parámetros presentados en la TABLA 3.

\section{Tratamiento de datos}

Los datos compilados consisten de un conjunto de lineamientos (identificados a partir de los mapas de referencias y de imágenes satelitales) y de datos de campo. El tratamiento de este conjunto de datos sigue los tres pasos propuestos por Mabee et al. (1994), con el fin de generar un mapa final con los lineamientos más representativos: (1) digitalización de todos los lineamientos identificables (ya fuese por consulta bibliográfica o por inspección visual de imágenes satelitales y DEM; (2) test de reproducibilidad con el cual se buscó superponer los lineamientos para descartar repeticiones y verificar su credibilidad, comparando los publicados con los propuestos en este trabajo; (3) análisis de dominio de superposición donde se integraron todos los datos estructurales de fracturas o lineamientos observados para la posterior construcción de un diagrama rosa, con el fin de determinar el dominio de fracturamiento.

En la compilación de lineamientos a partir de datos satelitales se consideraron rasgos lineales que presentaran extensión considerable y posible relación espacial con volcanes, y se compararon con información bibliográfica y datos de campo. La selección de datos en fotografías aéreas a diferentes escalas tuvo en cuenta cambios morfológicos y cambios en la tonalidad de grises, observándose que algunos lineamientos no presentaban gran extensión y exhibían tendencias longitudinales y transversales, con dominio de las orientaciones transversales. Es probable que varios lineamientos no pudieran ser detectados debido a la cobertura por depósitos recientes.

En lo referente a datos documentados, publicaciones y otros documentos de investigación, se tuvieron en cuenta principalmente las siguientes fuentes autoritativas: Gómez et al. (2015), Paris et al. (2000) y trabajos de grado de la Universidad Nacional de ColombiaSede Bogotá: Perdomo et al. (1986), Romero (2005), Rodríguez (2005), Pachón (2006), y se incluyeron datos comprendidos en un polígono con las siguientes coordenadas en sus vértices: 630.000 (límite norte, aproximadamente la latitud de la población de Ricaurte en Colombia), 570.000 (límite sur, aproximadamente a 
la latitud de la frontera con Ecuador), 850.000 (límite oeste) y 930.000 (límite este, cerca al municipio de Guachucal). En estos datos se observó principalmente tendencia regional longitudinal, con ejemplos reconocidos como la falla de Guachucal, la falla Piedrancha, y la falla Cuercuel, entre otras.

TABLA 2. Datos estructurales integrados (códigos de este trabajo: LCBR-XX y los siguientes códigos son relacionados por García, 2016) con sus coordenadas respectivas en datum Pacífico.

\begin{tabular}{|c|c|c|c|}
\hline Estación & $\mathbf{X}$ & $\mathbf{Y}$ & Observaciones \\
\hline LCBR-01 & 935880 & 620481 & Fallas (normales) con tendencia N55E y N60E, desplazamiento $(\sim 1 \mathrm{~m})$. \\
\hline LCBR-02 & 935162 & 621727 & Fallas en lavas andesíticas. La roca presenta trituración (harina de falla). 296/69,123/71,N76W/79. \\
\hline LCBR-03 & 930809 & 600500 & N55E (¿Falla de Guachucal?). \\
\hline LCBR-04 & 938236 & 604498 & Lavas de textura porfirítica. N545E/44SE. \\
\hline LCBR-05 & 906516 & 585474 & Lavas fuertemente meteorizadas, intenso diaclasamiento. 272/37S, 16/37SE,330/89SE, 6/38SE,87/41S \\
\hline LCBR-06 & 906459 & 585490 & $\begin{array}{l}25 / 45 \mathrm{SW} \text { (fractura, harina de falla) } 94 / 46 \mathrm{SW} 7 / 85 \mathrm{~W} \text {. Diaclasamiento intenso. Algunas diaclasas presentan } \\
\text { alteración hidrotermal, colores amarillos-verdes pálidos. }\end{array}$ \\
\hline LCBR-07 & 906485 & 585479 & 347/60SW. No se observa desplazamiento, alteración hidrotermal, minerales (cristales de sales). \\
\hline LCBR-08 & 906348 & 585655 & $\begin{array}{l}\text { 85/90. Diaclasas perpendiculares a diaclasas de enfriamiento, una de estas tendencias de diaclasas presenta } \\
\text { alteración de color blanco, geometría sinuosa, no es posible tomar un dato estructural representativo. }\end{array}$ \\
\hline LCBR-09 & 906405 & 585558 & $\begin{array}{l}\text { 75/75SE. Material triturado (harina de falla) de tamaño limo, presencia de óxidos y alteración hidrotermal. } \\
\text { Roca basáltica melanocrática de color verde oscuro, textura porfirítica fina, fenocristales de plagioclasa } \\
\text { tabulares (¿Plag. cálcica?). Alteración de olivinos a epidota. }\end{array}$ \\
\hline LCBR-10 & 905946 & 586196 & N47E/51NW, 270 13SW, 90/72S. Lavas basálticas fuertemente alteradas. \\
\hline LCBR-10.1 & 905997 & 586135 & $\begin{array}{l}\text { 259/68SE. Material triturado (cataclasita) } 2 \mathrm{~m} \text { de longitud sin desplazamiento evidente, material tamaño } \\
\text { arena fina. }\end{array}$ \\
\hline LCBR-11 & 905747 & 586353 & 40/9NW, 345/8NE. Roca intensamente diaclasada y fracturada, presenta varios sistemas de diaclasas. \\
\hline LCBR-12 & 905403 & 586303 & Roca fuertemente fracturada. Toma de datos para análisis $R M R$. Presencia de manantial. \\
\hline LCBR-13 & 904912 & 585897 & $\begin{array}{l}\text { 47/80SE, 22/73SE (presenta alteración hidrotermal). Lava basáltica de textura porfirítica fuertemente } \\
\text { alterada. Se observan tres posibles fracturas. }\end{array}$ \\
\hline LCBR-13.1 & 904207 & 585852 & 180/80W. Roca triturada con tamaño arena fina, textura granular, muy alterada y oxidada. \\
\hline LCBR-14 & 905040 & 580357 & $\begin{array}{l}\text { Zona de textura brechoide, lavas con textura porfirítica, los cristales presentan orientación (¿por flujo?). Se } \\
\text { observa fractura, alteración de colores verdosos. } 101,335 / 64 \mathrm{SW} \text {. Datos para análisis } R M R \text {. }\end{array}$ \\
\hline LCBR-15 & 903255 & 580179 & $\begin{array}{l}\text { 338/86NE, 345/75SE. Posible fractura en sentido N20E, se observa alteración de color verdoso. } \\
\text { Alteraciones siguen el sentido de las diaclasas de enfriamiento. Presencia de varios sistemas de diaclasas. }\end{array}$ \\
\hline 1 & 912904 & 579664 & Diaclasas de enfriamiento. \\
\hline 2 & 909900 & 580822 & Fracturas métricas en depósito de lahar. \\
\hline 3 & 908513 & 581035 & Fracturas métricas abiertas. \\
\hline 4 & 908177 & 581001 & Fracturas, alteración hidrotermal, diaclasas con estructura en rampa. \\
\hline 6 & 907412 & 579686 & Al E afloran lavas muy diaclasadas, se midió el dato de una familia con dirección N25E/72NW. \\
\hline 7 & 907254 & 579605 & $\begin{array}{l}\text { Diaclasas con dirección N10W/65SE, fracturas métricas buzando al SE. En algunas paredes de diaclasas se } \\
\text { aprecian estructuras lineales no identificadas (¿estrías glaciares?). }\end{array}$ \\
\hline 8 & 906629 & 579605 & Diaclasas con dirección preferencial N54E/15SW, intenso diaclasamiento con múltiples orientaciones. \\
\hline 10 & 905388 & 579930 & Diaclasas verticales métricas con dirección SE. \\
\hline 11 & 906328 & 579634 & Diaclasas con múltiples orientaciones definen bloques con formas de prismas en la roca. \\
\hline 12 & 904969 & 579737 & Diaclasas con aperturas milimétricas, fracturas métricas de aperturas milimétricas a centimétricas. \\
\hline 15 & 903427 & 579728 & $\begin{array}{l}\text { Muy alteradas y diaclasadas, algunas familias de diaclasas (subhorizontales) con superficies de oxidación } \\
\text { que reducen la permeabilidad. }\end{array}$ \\
\hline 16 & 903302 & 579652 & $\begin{array}{l}\text { Intenso diaclasamiento, dos familias dominantes con direcciones } \mathrm{N} 55 \mathrm{~W} / 50 \mathrm{NE} \text { y } \mathrm{N} 36 \mathrm{E} / 57 \mathrm{SE} \text { que } \\
\text { producen patrones rómbicos y prismáticos de diferentes tamaños en la roca, el diaclasamiento favorece la } \\
\text { meteorización esferoidal. }\end{array}$ \\
\hline 17 & 902481 & 580531 & Diaclasamiento intenso. Familia de diaclasas verticales con orientación N24E. \\
\hline 18 & 902714 & 580711 & $\begin{array}{l}\text { Lavas columnares. Domina el diaclasamiento por enfriamiento (patrón normal, se intensifica de base a } \\
\text { techo). }\end{array}$ \\
\hline 21 & 899760 & 580671 & $\begin{array}{l}\text { Lavas muy alteradas y diaclasadas, en contacto discordante con depósito epiclástico (material retrabajado, } \\
\text { clastos redondeados orientación incipiente) suprayacido por depósitos de caída piroclástica y suelos. }\end{array}$ \\
\hline
\end{tabular}


TABLA 3. Parámetros del sistema de clasificación de un macizo rocoso (RMR) y sus valoraciones (resaltados en gris). Fuente: García (2016).

\begin{tabular}{|c|c|c|c|c|c|c|c|c|}
\hline $\begin{array}{l}\text { Resistencia } \\
\text { de la roca } \\
\text { intacta }\end{array}$ & $\begin{array}{c}\text { Resistencia a } \\
\text { compresión } \\
\text { uniaxial (MPa) }\end{array}$ & $>250$ & $100-250$ & $50-100$ & $25-50$ & $5-25$ & $1-5$ & $<1$ \\
\hline \multirow[t]{2}{*}{1} & Valoración & 15 & 12 & 7 & 4 & 2 & 1 & 0 \\
\hline & (\%) RQD & $90-100$ & $75-90$ & & $50-75$ & $25-50$ & & $<25$ \\
\hline \multirow[t]{2}{*}{2} & Valoración & 20 & 17 & & 13 & 8 & & 3 \\
\hline & $\begin{array}{l}\text { Espaciamiento de } \\
\text { discontinuidades } \\
\text { (m) }\end{array}$ & $>2$ & $0,6-2$ & & $0,2-0,6$ & $0,06-0,2$ & & $<0,06$ \\
\hline \multirow[t]{2}{*}{3} & Valoración & 20 & 15 & & 10 & 8 & & 5 \\
\hline & $\begin{array}{c}\text { Condición de } \\
\text { discontinuidades }\end{array}$ & $\begin{array}{l}\text { Muy rugosa, } \\
\text { discontinuidades, } \\
\text { no separación, } \\
\text { sin erosión }\end{array}$ & $\begin{array}{l}\text { Paredes } r \\
\text { separación } \\
\text { algo mete }\end{array}$ & $\begin{array}{l}\text { ugosas, } \\
<0,1 \mathrm{~mm} \text {, } \\
\text { eorizada }\end{array}$ & $\begin{array}{l}\text { Levemente } \\
\text { rugosas, } \\
\text { separación } \\
<1 \mathrm{~mm}, \\
\text { altamente } \\
\text { meteorizada }\end{array}$ & $\begin{array}{r}\text { Cara suave } \\
<5 \text { mm es } \\
\text { separación } \\
\text { de } \\
1-5\end{array}$ & $\begin{array}{l}\text { o harina } \\
\text { esor, o } \\
\text { continua } \\
\text { nm }\end{array}$ & $\begin{array}{c}\text { Harina suave } \\
\text { espesor }> \\
5 \mathrm{~mm} \text { o } \\
\text { separación } \\
\text { continua }>5 \\
\text { mm, roca caja } \\
\text { descompuesta }\end{array}$ \\
\hline 4 & Valoración & 30 & 25 & & 20 & 10 & & 0 \\
\hline $\begin{array}{c}\text { Agua } \\
\text { subterránea }\end{array}$ & $\begin{array}{l}\text { Condiciones } \\
\text { generales }\end{array}$ & $\begin{array}{c}\text { Completamente } \\
\text { seca }\end{array}$ & Húm & eda & Mojada & Empa| & ada & Fluida \\
\hline 5 & Valoración & 15 & 10 & & 7 & 4 & & 0 \\
\hline
\end{tabular}

La aplicación del método RMR fue posible en cinco afloramientos, con longitudes características de análisis de $1 \mathrm{~m}$ (para afloramientos accesibles, principalmente cerca de las vías) y 20 m (sobre fotografías).

Por último, se relacionaron los datos obtenidos en campo con los lineamientos generados por el procesamiento del DEM y las imágenes LANDSAT, sobre la misma área estudiada con las fallas reportadas en la bibliografía. De manera general, los lineamientos identificados en el DEM y las imágenes satelitales se asocian a los patrones de drenaje y a los cambios de pendiente. Los datos estructurales medidos en algunas estaciones de campo coinciden con lo observado en imágenes. A nivel regional, muchos lineamientos presentan tendencia longitudinal.

\section{RESULTADOS}

La minería de datos, el análisis de imágenes satelitales y la confirmación de campo permitieron la construcción de tres mapas con estructuras en la región de interés del PGB. El primer mapa, denominado mapa de referencias, se considera preliminar, es de extensión regional (ver sección Tratamiento de Datos) e incluye estructuras no repetidas identificadas a partir de la minería de datos de fallas reportadas en la bibliografía. Este mapa incluye 28 estructuras, de las cuales ocho cruzan el área de interés del PBG (FIGURA 3). Los lineamientos se asocian a los drenajes, los cambios de pendiente y otros patrones lineales en sentido general N60E - N80E (FIGURA 4) concordantes con la tendencia reportada por Perdomo et al. (1986).

El mapa generado a partir de la inspección de imágenes satelitales LANDSAT, fotografías aéreas y DEM incluye 50 lineamientos, 14 de ellos con algún segmento dentro del polígono del PGB (FIGURA 5). Las imágenes no permiten establecer el tipo de falla y es posible que los lineamientos extensos formen parte de sistemas de fallas como las presentadas en la FIGURA 3. Por ejemplo, la falla que se propone longitudinalmente al oeste del área de interés podría ser asociada a la falla Cauca-Patía (Ujueta, 2001). Además de la tendencia longitudinal usual, resaltan estructuras de tendencia transversal. La FIGURA 6, muestra la orientación de las estructuras propuestas en la FIGURA 5.

Por último, se construyó un mapa local final de lineamientos, que enfatiza las estructuras propuestas para el área de interés del PGB, y tiene en cuenta datos de las observaciones de campo (FIGURA 7), por ejemplo, los tipos de afectación de las rocas. En la zona se documentan varias familias de diaclasas y fracturas, siendo las diaclasas más comunes aquellas producidas durante el enfriamiento de los diferentes 
flujos de lava, aunque también se observaron diaclasas perpendiculares a las diaclasas de enfriamiento, con direcciones preferenciales NW y EW. Las orientaciones de abundantes planos de diaclasas fueron medidas (dependiendo de condiciones de acceso) y en la FIGURA 8 se muestran las tendencias variables de estos planos, observados en los afloramientos relacionados en la TABLA 2.

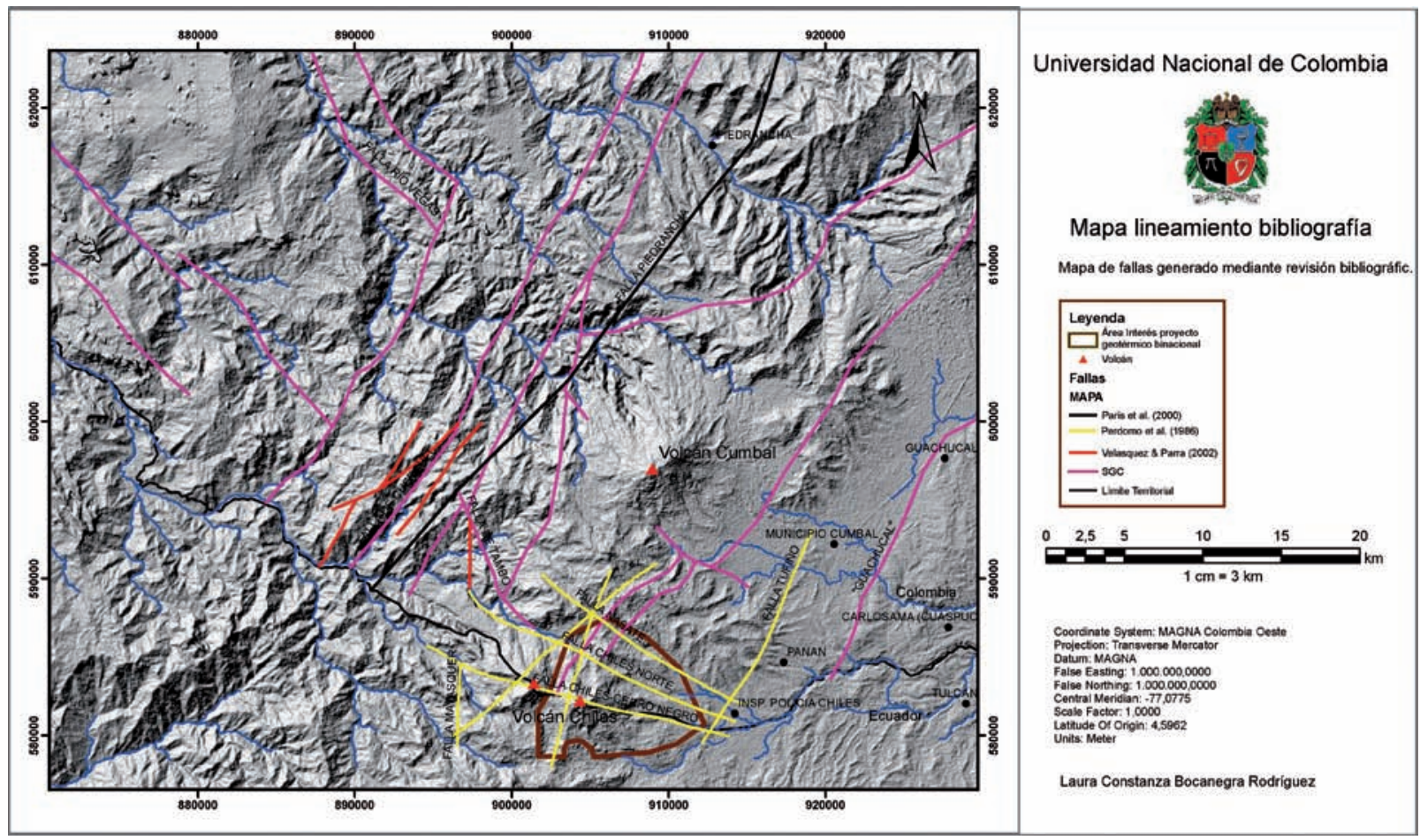

FIGURA 3. Mapa preliminar de fallas sobre modelo de elevación digital, construido a partir de búsqueda en fuentes publicadas. Líneas amarillas: Perdomo et al. (1986). Línea negra: Paris et al. (2000). Líneas rojas: Velásquez y Parra (2002). Líneas violetas: Gómez et al. (2015). Otras convenciones como en la FIGURA 1.
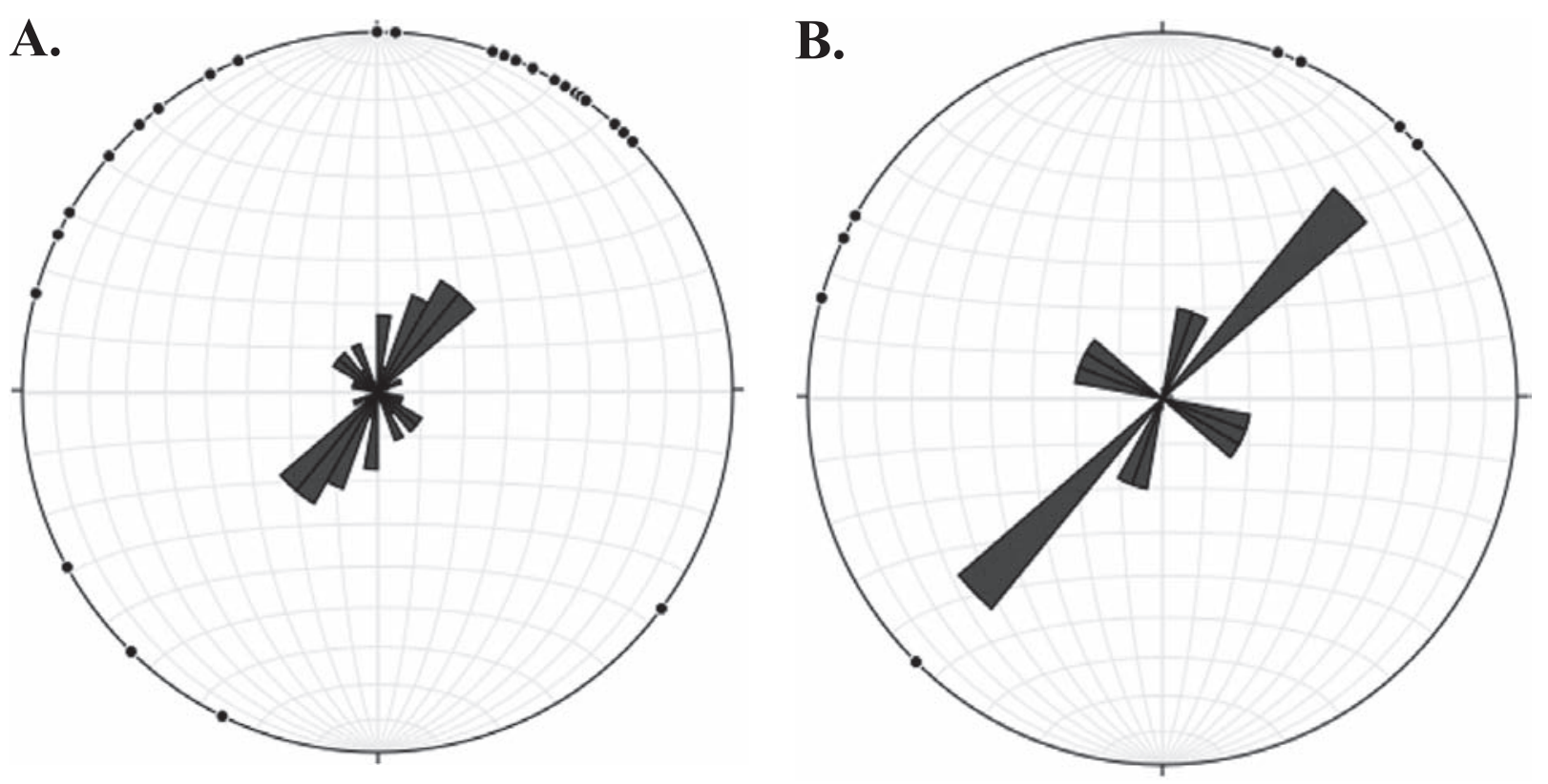

FIGURA 4. Diagrama rosa con la orientación de los lineamientos incluidos en la FIGURA 3. A. Todas las estructuras (28 en total). B. Ocho estructuras que cruzan el área del PGB. 


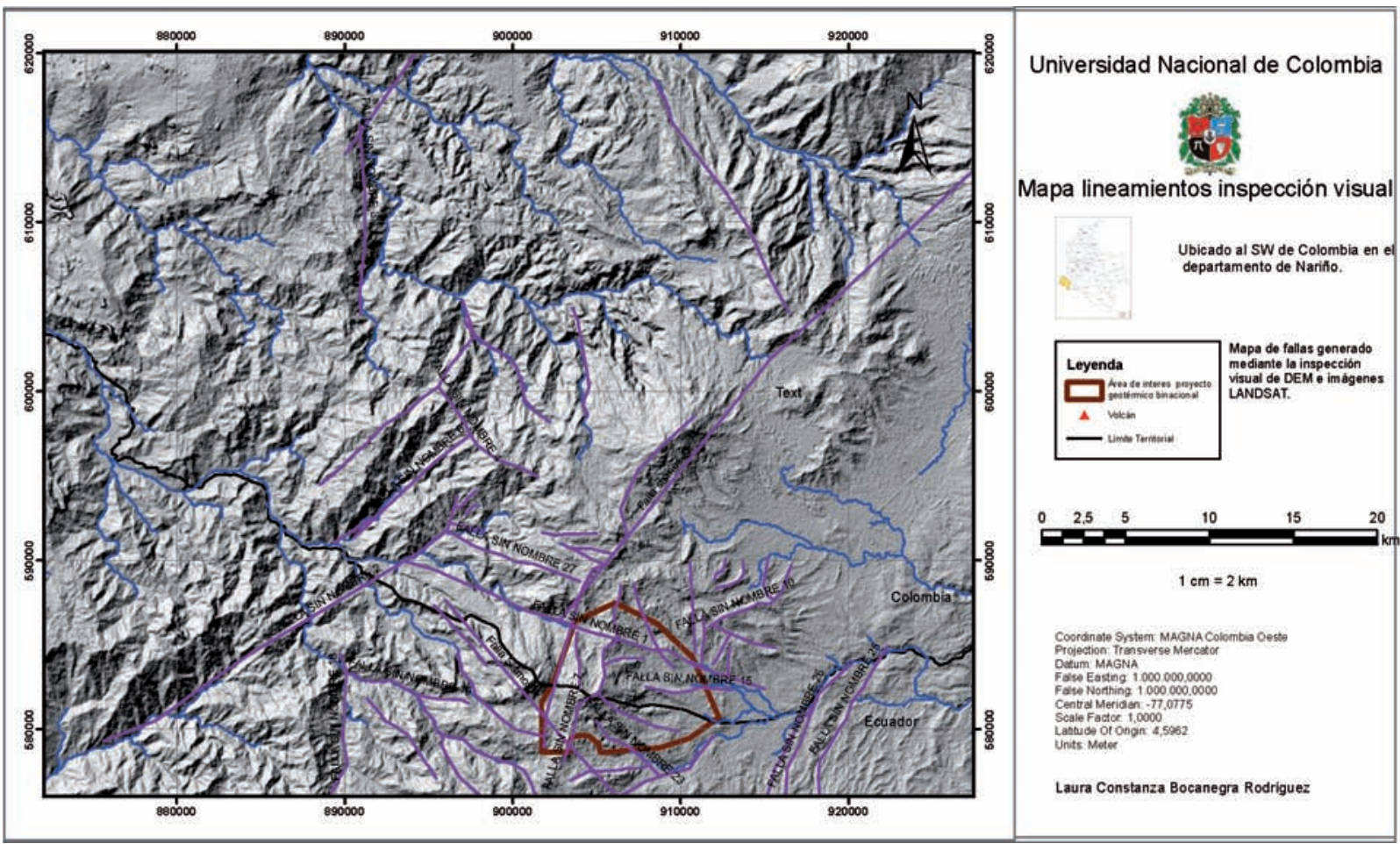

FIGURA 5. Mapa de relieve sombreado con lineamientos (línea violeta) propuestos a partir de procesamiento y análisis de imágenes satelitales. Convenciones como en la FIGURA 1.
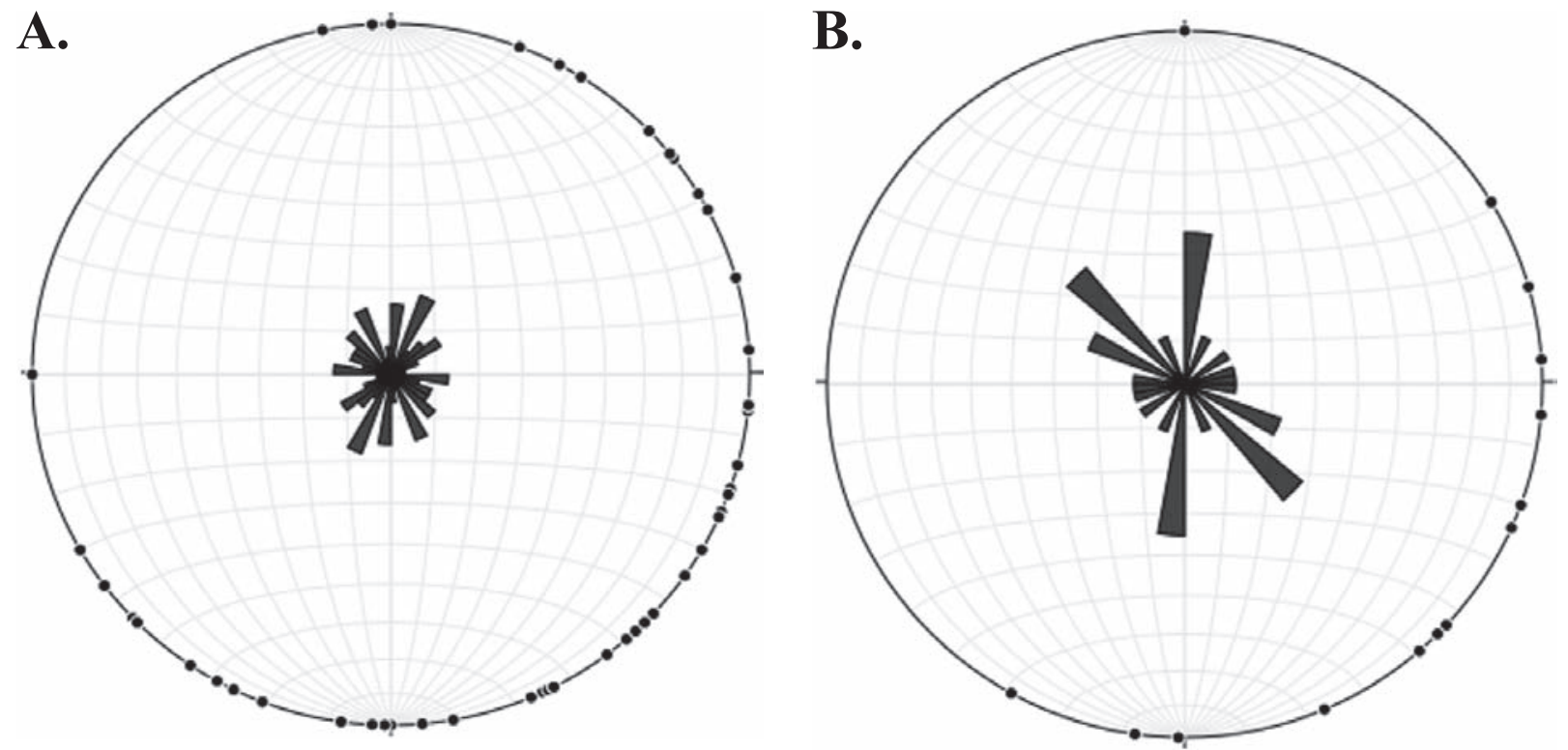

FIGURA 6. Diagrama rosa con la orientación de los lineamientos incluidos en la FIGURA 5. A. Todas las estructuras (50 en total). B. Catorce estructuras que cruzan el área del PGB.

La información acerca de discontinuidades (fallas, diaclasas, fracturas) fue utilizada para la clasificación geomecánica de las rocas en el sistema RMR en cinco afloramientos del área de estudio. Los resultados y el procedimiento de cálculo se presentan en el
ANEXO, el cual incluye fotos con estructuras típicas observadas y tablas con listas de parámetros relevantes calculados. Mediante los cálculos propuestos en Jerram y Petford (2011) se calcularon RMR superiores a 70 (ver ANEXO), siendo el valor más alto el quinto 
afloramiento con un RMR de 82. En este lugar había presencia de agua con una temperatura elevada, donde en un tiempo fue utilizado como balneario (aguas hediondas).

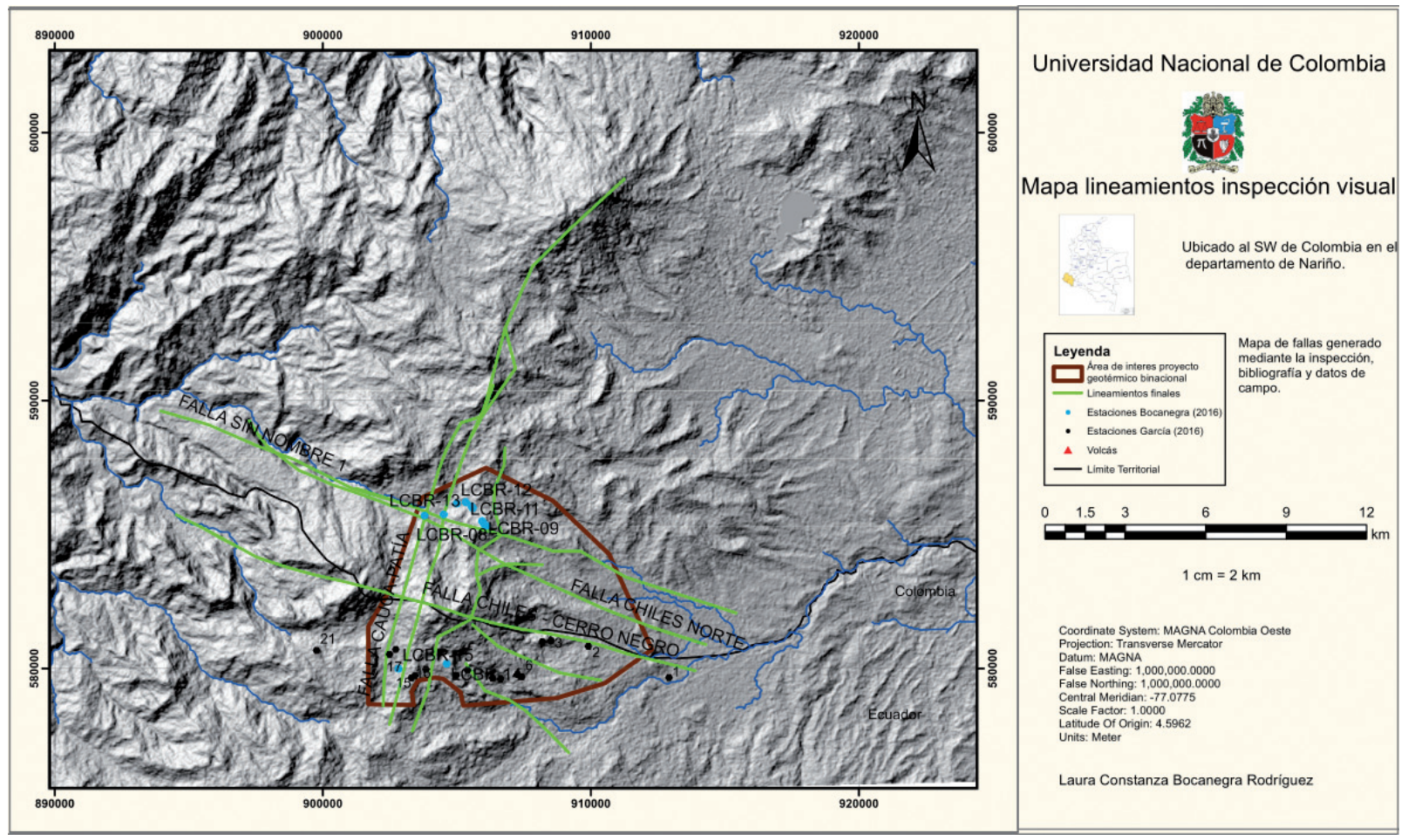

FIGURA 7. Mapa de relieve sombreado con los principales lineamientos en el área de estudio. Este mapa final se realizó mediante la integración de recopilación bibliográfica, análisis de imágenes y confirmación de campo. Se observa tendencia principal transversal, concordante con los datos obtenidos en campo (las diaclasas presentan tendencia general E-W). De otra parte, las fracturas observadas en campo presentan orientación en sentido NE, cuasi paralela al sentido de las fallas longitudinales.

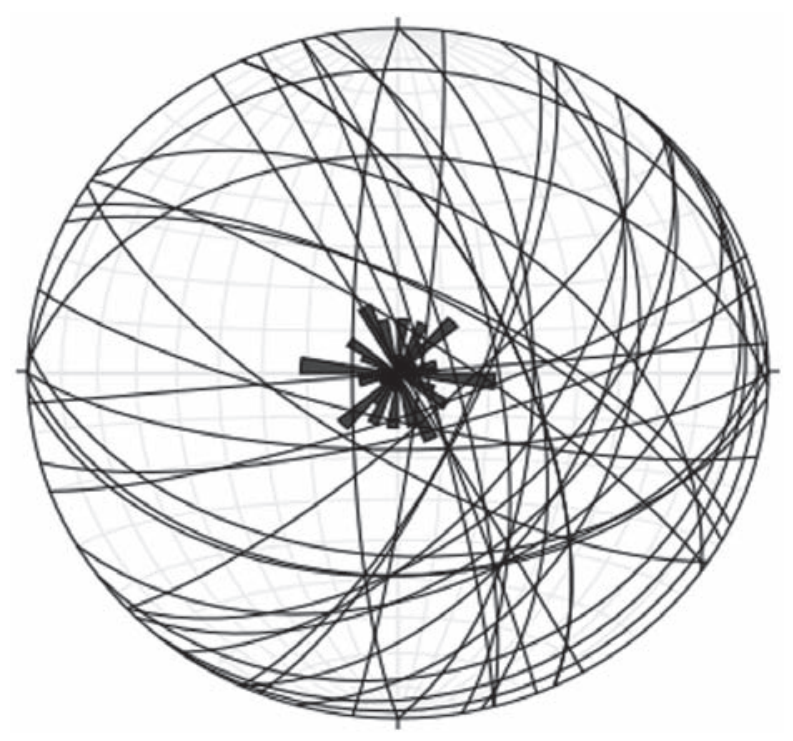

FIGURA 8. Proyección estereográfica y diagrama rosa para los datos estructurales de 38 planos de diaclasas obtenidas en campo. No se aprecia tendencia preferencial. Muchos planos concuerdan con los lineamientos de la FIGURA 7.

\section{DISCUSIÓN}

Se realizó la integración de datos acerca de lineamientos, fallas y discontinuidades en la región de interés del PGB obtenidos de tres fuentes independientes: información publicada, análisis de imágenes satelitales y DEM y observaciones de campo. La información publicada, correspondiente en su totalidad a artículos, mapas y reportes de trabajos de investigación realizados por fuentes autoritativas (ej. Gómez et al., 2015; Paris et al., 2000; Perdomo et al., 1986), tendría carácter repetitivo acerca de las fallas y estructuras, pero fue depurada para evitar redundancias. El proceso de minería de datos publicados permitió evidenciar que entre diferentes fuentes de información se documentaban estructuras que por su cercanía espacial (separaciones menores a 1-2 km) fueron consideradas como una misma falla. Otro factor que probablemente implicaría redundancia es la variabilidad en los datos geográficos de datum de referencia entre las distintas proyecciones y mapas. El análisis de las imágenes satelitales y el DEM resultó en algunas estructuras propuestas diferentes y complementarias a las publicadas (Rodríguez et al., 
2008) y corresponde esencialmente a interpretación de los autores mientras que los datos compilados en campo proveen confirmación de la existencia de daño en rocas (diaclasas, fracturas, harina de falla, brechas, discontinuidades rellenas) que espacialmente se asocian al trazo de varias estructuras documentadas (FIGURA 7).

La unión de los datos descritos resultó en mapas de fallas presentados en las FIGURAS 3, 5 y 7 en los cuales se observan tendencias regionales dominantes de carácter longitudinal (SW-NE), y transversal (SE-NW). Dentro de la zona de interés del PGB se documentan segmentos correspondientes a ocho fallas y lineamientos cuyo carácter en términos de exposición y sentido de movimiento está aún por esclarecerse y sería en objeto de investigaciones detalladas utilizando otras técnicas. No obstante, como una primera aproximación, los resultados pueden ser complemento de un modelo geotérmico conceptual en construcción (García, 2016), ya que las fallas reportadas pueden indicar las tendencias preferenciales para la circulación de fluidos, relacionados a los sistemas de recarga y descarga del sistema geotérmico o hidrológico. Además, la identificación de estos lineamientos puede ayudar a determinar la permeabilidad de la roca y a imponer restricciones en la geometría conceptual del sistema geotérmico.
Una fuente de información adicional acerca de la existencia de fallas activas en el área de estudio es la relacionada a epicentros de sismos detectados durante 1993-2016 (FIGURA 9). Muchos epicentros en el área corresponden a enjambres energéticos relacionados a actividad de los volcanes Chiles-Cerro Negro durante 2013-2015, pero también se observa sismicidad dispersa con tendencia general SE-NW que probablemente se origina en varias de las fallas y segmentos de fallas documentadas en la región y se sugiere un estudio de relocalización precisa de estos sismos para determinar si la relación espacial representa causalidad. De otra parte, las manifestaciones superficiales de actividad geotérmica como fuentes termales, fumarolas y zonas de alteración hidrotermal, pueden estar espacialmente asociadas a fallas y lineamientos (FIGURA 9) y aunque es posible que la ubicación de todas las manifestaciones no haya sido establecida (García, 2016), las actualmente documentadas constituyen información complementaria para la propuesta de algunas estructuras en la región.

Los datos obtenidos en campo y el análisis RMR sugieren rocas de buena resistencia, pero con presencia de fracturas que representan porosidad secundaria y mejoran la permeabilidad superficial, rasgos importantes a tener en cuenta en la exploración de recursos geotérmicos.

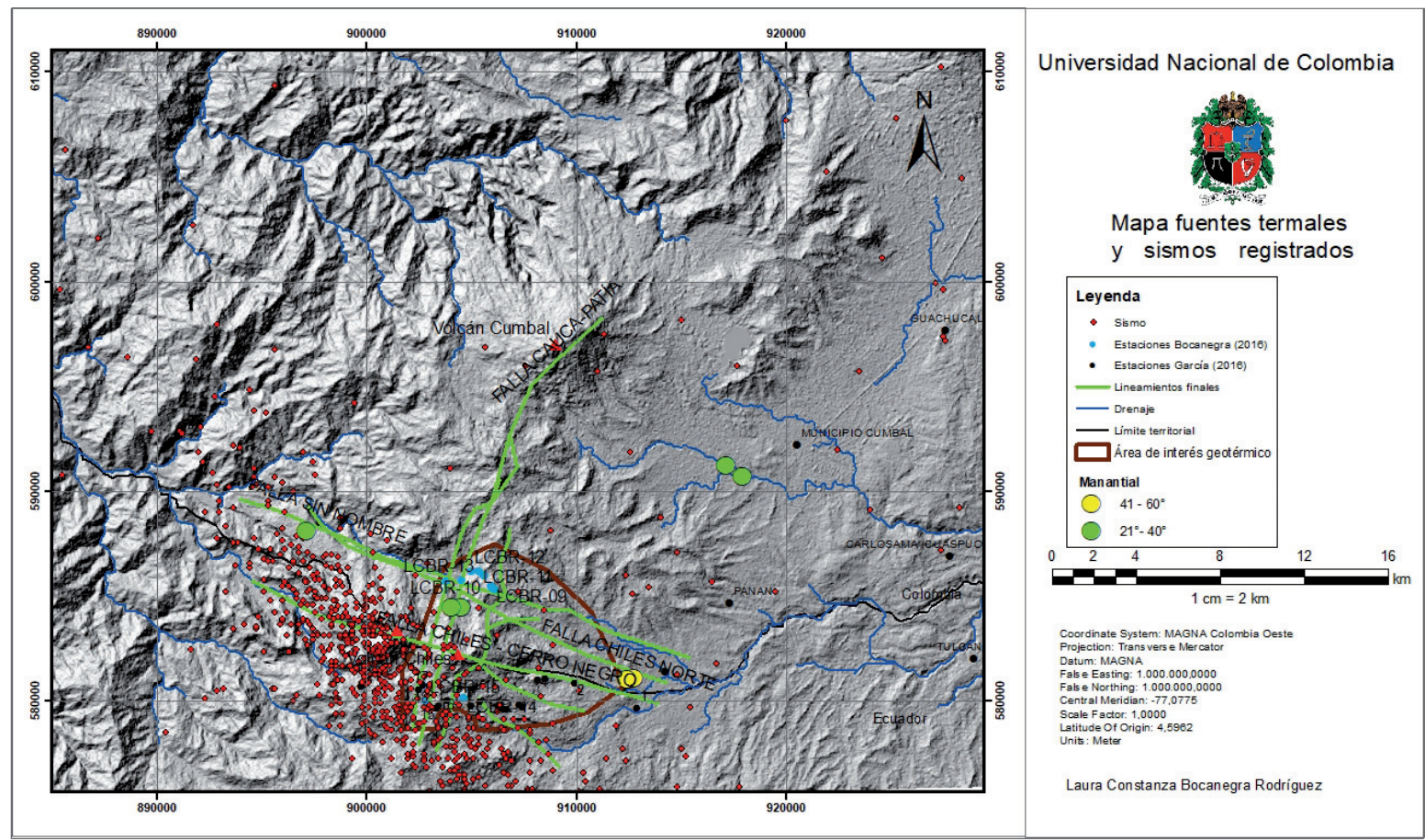

FIGURA 9. Mapa de la zona de estudio con las fallas propuestas cercanas al área de interés del PGB y la localización de epicentros de sismos (círculos rojos) reportados por el Servicio Geológico Colombiano-Red Sismológica Nacional de Colombia durante 1993-2016. Las profundidades de los sismos varían entre 0 y $30 \mathrm{~km}$. Los círculos verdes representan fuentes termales con temperaturas entre $21^{\circ} \mathrm{C}-40^{\circ} \mathrm{C}$ y los círculos de color amarillo representa fuentes termales de $41^{\circ} \mathrm{C}-60^{\circ} \mathrm{C}$. 


\section{CONCLUSIONES}

El uso de minería de datos en conjunto con análisis de imágenes satelitales y datos de campo permitió la creación de mapas con lineamientos y fallas para el área general de interés del denominado proyecto geotérmico binacional, que incluye la región de los volcanes Chiles y Cerro Negro de Mayasquer. Los resultados permiten las siguientes conclusiones:

- Existen dos tendencias principales en la orientación de las fallas y lineamientos en la zona de estudio, una en sentido SW-NE (longitudinal), y otra en sentido SE-NW (transversal).

- La inspección visual de imágenes satelitales sirvió como base para la búsqueda de evidencias de fallas en campo, debido a qe muchos segmentos de fallas probablemente están cubiertos por depósitos recientes que enmascaran la localización. Los datos obtenidos en campo muestran concordancia con las tendencias longitudinal (fracturas) y transversal (diaclasas), similar a observaciones reportadas en otros trabajos.

- Los lineamientos longitudinales presentan una mayor extensión que los lineamientos transversales tanto a nivel local como regional.

- En términos de la zona de interés geotérmico, la tendencia transversal de lineamientos presenta mayor importancia para futuras investigaciones. Esto debido a la cantidad de lineamientos que posiblemente afectan la zona. Estos lineamientos podrían relacionarse espacialmente con fuentes termales, fumarolas o zonas de alteración hidrotermal.

- El análisis RMR indicó valores superiores a 70, correspondientes a rocas geomecánicamente buenas. Las fracturas representan porosidad secundaria y mejoran la permeabilidad.

- Este trabajo es un insumo para complementar la construcción del modelo geotérmico conceptual de la región de los volcanes Chiles-Cerro Negro de Mayasquer.

\section{AGRADECIMIENTOS}

Los autores agradecen al Departamento de Geociencias, a la Facultad de Ciencias, a la Universidad Nacional de Colombia-Sedes Bogotá y Medellín por el apoyo académico y al Servicio Geológico Colombiano por los datos que amablemente ponen a disposición del público.

\section{REFERENCIAS}

Acosta, J., Velandia, F., Osorio, J., Lonergan, L., and Mora, H. 2007. Strike-slip deformation within the Colombian Andes. Geological Society, London, Special Publications, 272: 303-319.

Alfaro, C., Ponce, P., Monsalve, M.L., Ortiz, I., Franco, J.V., Ortega, A., Torres, R., and Gómez, D. 2015. A preliminary conceptual model of Azufral geothermal system, Colombia. Proceedings World Geothermal Congress, Melbourne, Australia, 10p.

Ayala, L.C. 2014. Aplicación de técnicas de magnetotelúrica en un área de interés geotérmico en cercanías a la Falla Nereidas al occidente del Volcán Nevado del Ruiz. Trabajo de Grado, Universidad Nacional de Colombia, Bogotá, Colombia. 33p.

Bayona, G., Cardona, A., Jaramillo, C., Mora, A., Montes, C., Valencia, V., Ayala, C., Montenegro, O., and Ibañez-Mejia, M. 2012. Early Paleogene magmatism in the northern Andes: Insights on the effects of Oceanic Plateau-continent convergence. Earth and Planetary Science Letters, 331-332: 97-111.

Coronado, Y.C. 2014. Uso de sondeos de magnetotelúrica para la correlación con la geología de un área al occidente del Volcán Nevado del Ruiz. Trabajo de Grado, Universidad Nacional de Colombia, Bogotá, Colombia. 19p.

Duncan, R.A., and Hargraves, R.B. 1984. Plate tectonic evolution of the Caribbean region in the mantle reference frame. In: Bonini, W.E., Hargraves, R.B., and Shagam, R. (Eds.). The Caribbean-South American Plate Boundary and Regional Tectonics. Geological Society of America Memoirs, vol. 162, 421p.

García, Y.K. 2016. Contribuciones geológicas al modelo geotérmico conceptual en la región de los volcanes Chiles - Cerro Negro. Trabajo de Grado, Universidad Nacional de Colombia, Bogotá, Colombia. 34p.

Gómez, J., Nivia, A, Montes, N.E., Diederix, H., Almanza, M.F., Alcárcel, F.A., and Madrid, C.A. 2015. Explanatory notes: Geological Map of Colombia. In: Gómez, J., and Almanza, M.F. (Eds.). Compilando la geología de Colombia: Una visión a 2015. Servicio Geológico Colombiano, Publicaciones Geológicas Especiales, vol. 33, pp. 35-60. 
INGEOMINAS. 2009. Guía metodológica para el reconocimiento geológico en campos geotérmicos. Informe Interno, 31p.

Jaillard, E., Ordoñez, M., Suárez, J., Toro, J., Iza, D., and Lugo, W. 2004. Stratigraphy of the late CretaceousPaleogene deposits of the Cordillera Occidental of central Ecuador: Geodynamic implications. Journal of South American Earth Sciences, 17(1): 49-58.

Jerram, D., and Petford, N. 2011. The field description of igneous rocks. John Wiley \& Sons, 256p.

Mabee, S.B., Hardcastle, K.C., and Wise, D.U. 1994. A method of collecting and analyzing lineaments for regional-scale fractured-bedrock aquifer studies. Groundwater, 32(6): 884-894.

Marzolf, N. 2014. Emprendimiento de la energía geotérmica en Colombia. Convenio ISAGEN- Banco Interamericano de Desarrollo. Monografía. 89p.

Moyano, I. 2015. Modelamiento de estructuras geotérmicas ocultas a partir de la interpretación de anomalías magnetotelúricas de resistividad en la región de Paipa, Boyacá, Colombia. Tesis de Maestría, Universidad Nacional de Colombia, Bogotá, Colombia. 114p.

Pachón, M. 2006. Análisis de los patrones de fracturamiento en el Altiplano Nariñense. Trabajo de Grado. Universidad Nacional de Colombia, Bogotá, Colombia. 36p.

Paris, G., Machette, M.N., Dart, R.L., and Haller, K.M. 2000. Map and database of quaternary faults and folds in Colombia and its offshore regions. U.S. Geological Survey Open-File Report 00-0284.

Perdomo, G., Ardila, R., y Meneses, L. 1986. Estudio geológico para prospección de azufre en el área de Cumbal - Chiles - Mayasquer (Nariño). Trabajo de Grado, Universidad Nacional de Colombia, Bogotá, Colombia. 145p.

Pinilla, A., Ríos, P.A., Rodríguez, B.P, Roa, H.J., y Ladino, F.A. 2007. Memoria explicativa de la cartografía geológica y geomorfológica del Altiplano Nariñense. Proyecto de Investigación Sísmica, Geológica y Geotérmica en el Altiplano Nariñense, Tomo I. INGEOMINAS, Universidad Nacional de Colombia, $176 \mathrm{p}$.
Prieto, A.M. 2006. Diagnóstico del potencial geotérmico en la zona del proyecto geotérmico binacional Tufiño Chiles Cerro Negro. Trabajo de Grado, Universidad Nacional de Colombia, Bogotá, Colombia. 36p.

Rodríguez, B. 2005. Procesamiento e interpretación estructural de imágenes satelitales del Altiplano Nariñense. Trabajo de Grado. Universidad Nacional de Colombia, Bogotá, Colombia. 20p.

Rodríguez, B.P., Velandia, F., y Cárdenas, R. 2008. Teledetección y SIG aplicados a la exploración geológico-geofísica en el Altiplano Nariñense Colombia. Geología Colombiana, 33: 79-90.

Romero, D. 2005. Análisis preliminar de la geología estructural del altiplano nariñense como apoyo a la exploración regional de aguas subterráneas. Trabajo de Grado. Universidad Nacional de Colombia, Bogotá, Colombia. 18p.

Ujueta, G. 2001. Lineamientos de dirección NO-SE y NNE-SSO a NE-SO en el Centro Occidente Colombiano y en el Ecuador. Geología Colombiana, 26: 5-27.

USGS. 2016. Earth Explorer. United States Geological Survey. Consultado el 15 de noviembre de 2016. https:// earthexplorer.usgs.gov/

Velásquez, M., y Parra, E. 2002. Geología de las planchas 447 - Ipiales y 447 BIS - Tallambí, Departamento de Nariño. Memoria Explicativa, Escala 1:100000. INGEOMINAS. Bogotá.

Trabajo recibido: abril 04 de 2017

Trabajo aceptado: agosto 31 de 2017 


\section{ANEXO}
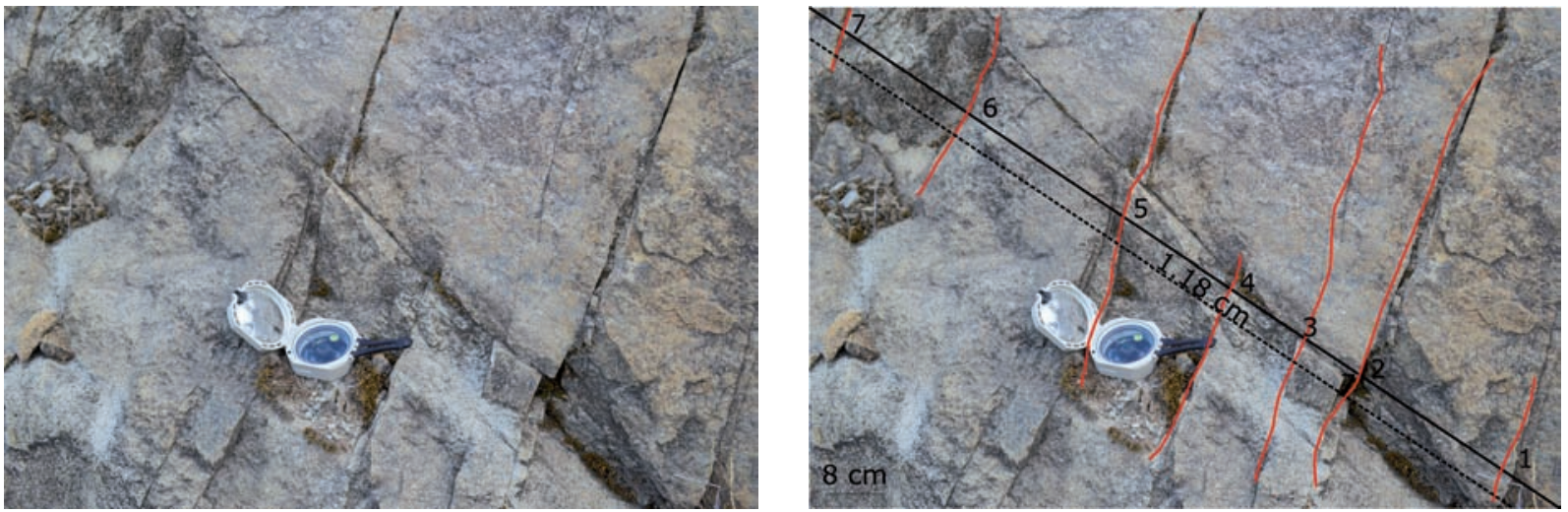

\section{RMR 1 (ESTACIÓN LCBR-04)}

Lavas andesíticas con textura porfirítica. Fracturas y diaclasas métricas de aproximadamente medio metro, cerradas sin presencia de alteraciones. Dato estructural 045/44SE. Se observa que tanto las diaclasas como fracturas son casi paralelas. El análisis RMR fue realizado a lo largo de una longitud de referencia aproximada de $1 \mathrm{~m}$ (línea recta negra).
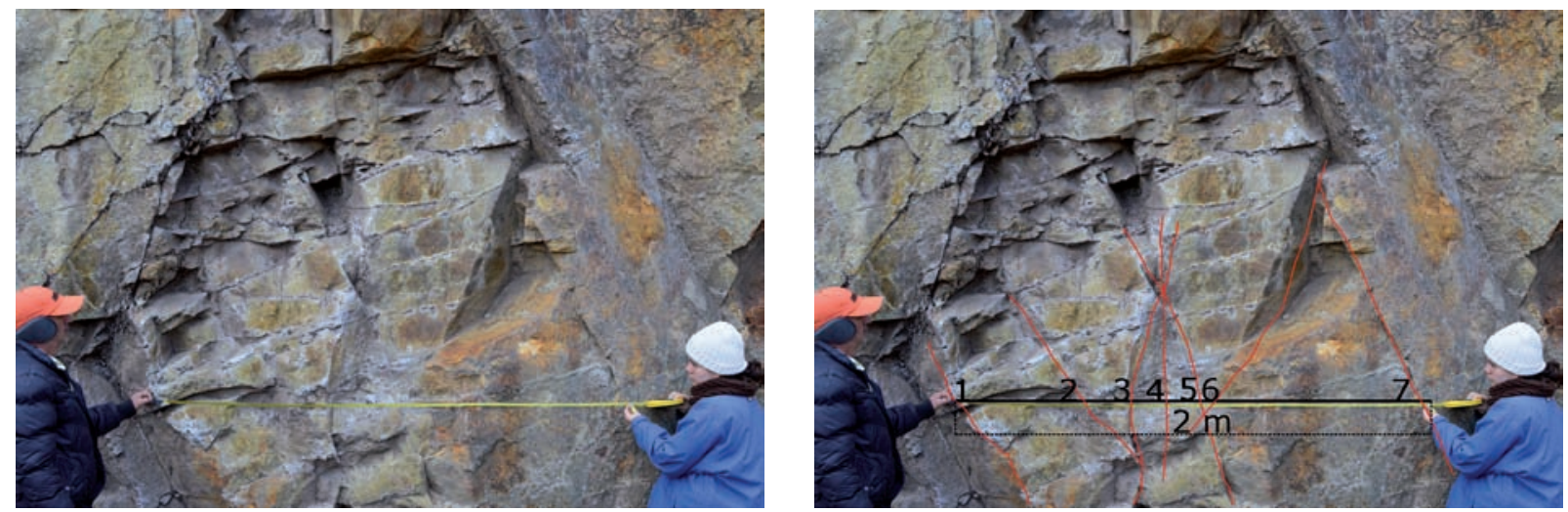

\section{RMR-2 (ESTACIÓN LCBR- 12)}

Lavas, la roca presenta leve meteorización, con óxidos de hierro y coloraciones verdosas (izquierda y centro de la fotografía). La fractura 3 presenta una leve alteración. Fracturas y diaclasas métricas cerradas. El análisis RMR fue realizado a lo largo de una longitud de referencia de $2 \mathrm{~m}$ (línea recta negra).
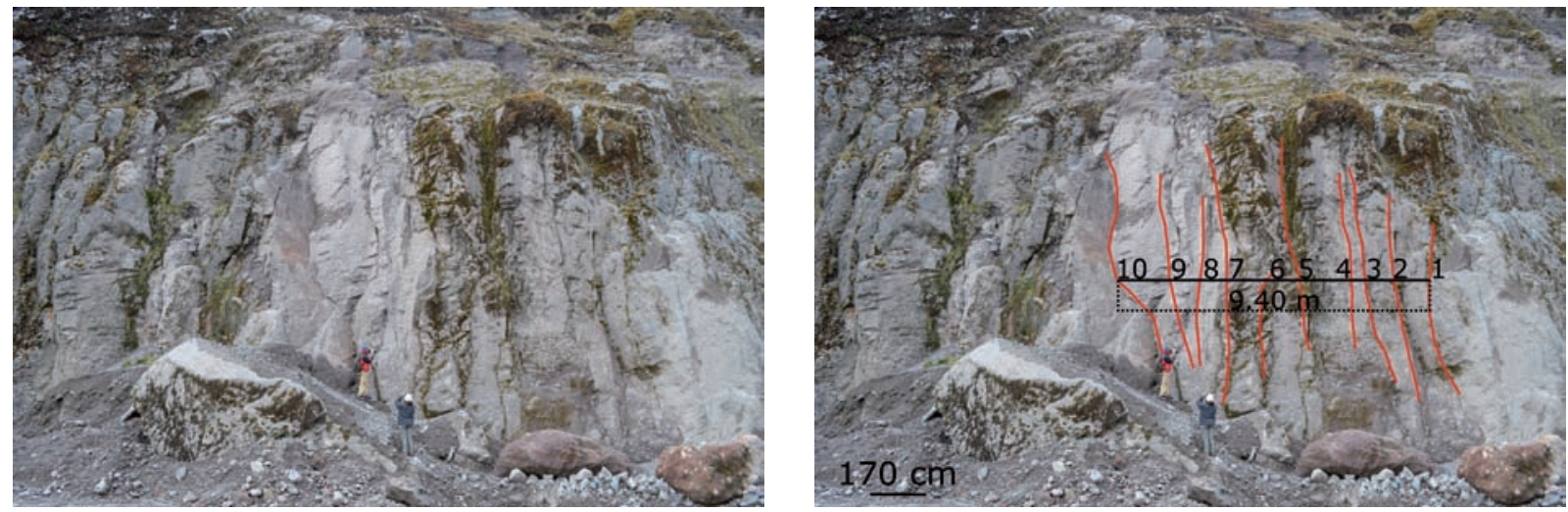
Afloramiento tipo cantera. Zona de brechamiento, la roca presenta varias tonalidades debidas a alteraciones. Fracturas y diaclasas métricas. La fractura 3 exhibe apertura de aproximadamente $20 \mathrm{~cm}$. Fractura 7 con tonos rosados de alteración leve. El análisis RMR se llevó a cabo a lo largo de una longitud de referencia aproximada de 11 m (línea recta negra).
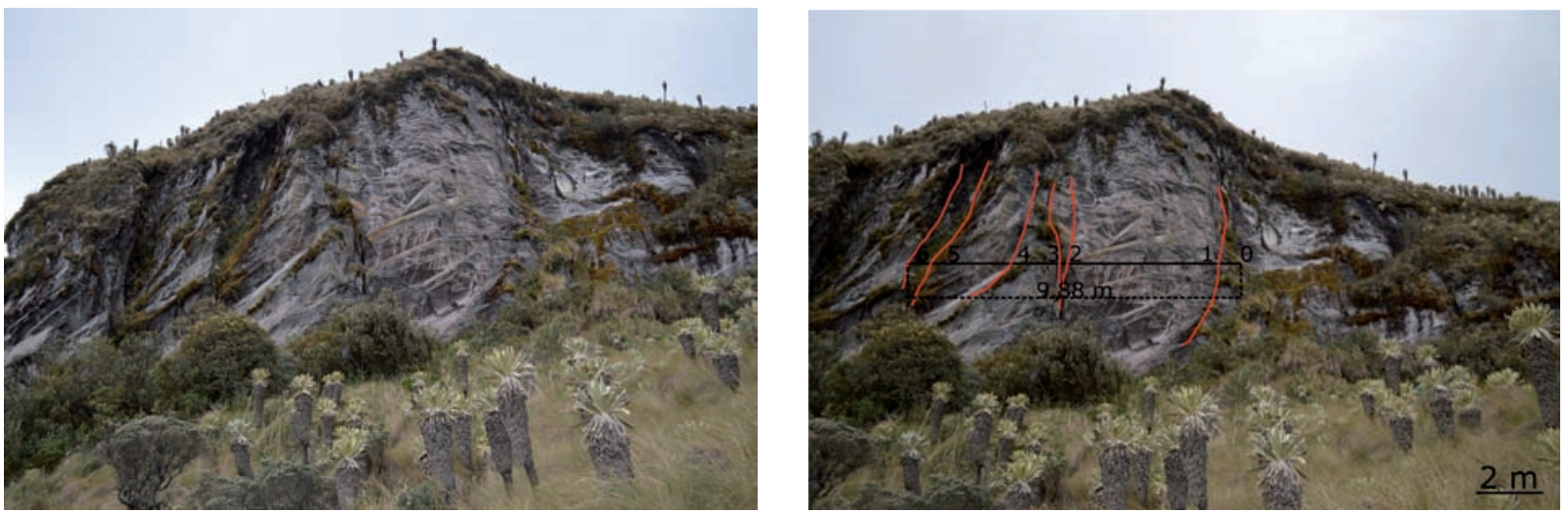

\section{RMR-4 (VÍA TUFIÑO-MALDONADO)}

Análisis RMR para rocas observadas en la vía Tufiño-Maldonado (Ecuador). Se observan fracturas abiertas (ejemplo: fractura 3) y cerradas y presencia de alteraciones de colores claros. Fracturas y diaclasas de aproximadamente 1- 3 $\mathrm{m}$. Algunas fracturas son sinuosas. El análisis RMR se realizó a lo largo de una longitud de referencia de 10 metros (línea recta negra).
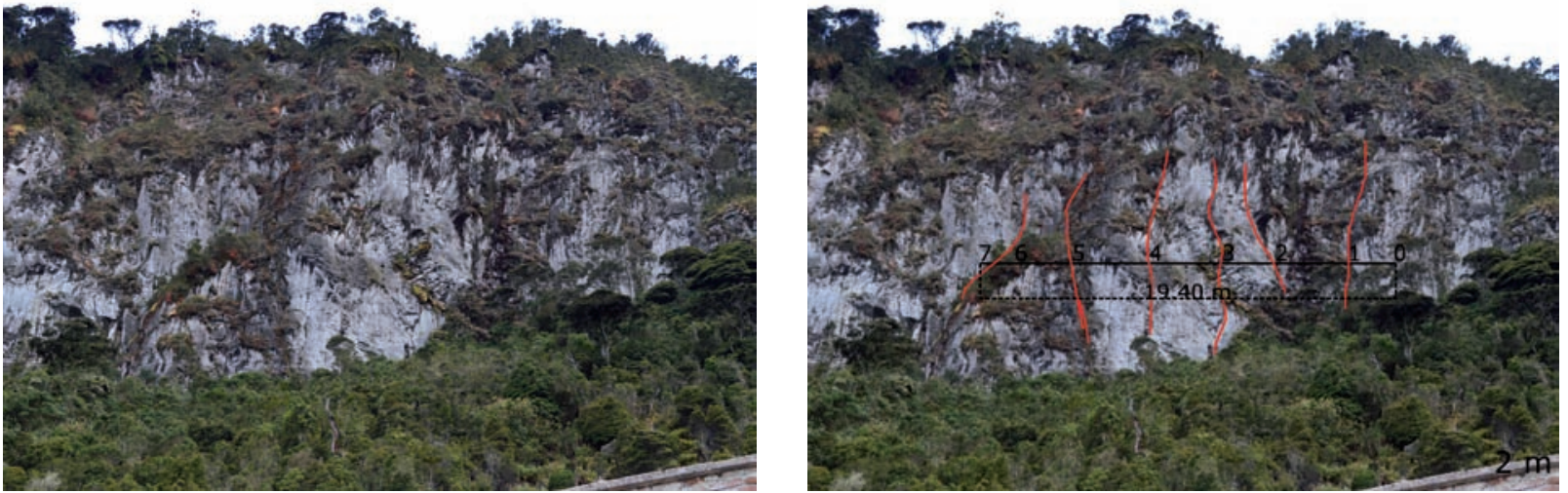

\section{RMR-5 (SECTOR AGUAS HEDIONDAS)}

Análisis RMR a rocas observadas en el sector "Aguas Hediondas" (fuentes termales) en Ecuador. Se observaron diaclasas y fracturas métricas cerradas. Leve alteración en la fractura 4 con tonos verdes claros. El análisis RMR se realizó a lo largo de una longitud de referencia de 20 m (línea recta negra).

Las medidas en cada una de las estaciones están resumidas en la TABLA 4.

TABLA 4. Distancias reales entre discontinuidades (en afloramiento, a lo largo de la línea de referencia mostrada en cada foto). Los números en la primera fila corresponden a las discontinuidades numeradas en cada foto.

\begin{tabular}{lcccccccccc}
\hline Distancia (m) & 0 a 1 & $\mathbf{1}$ a 2 & $\mathbf{2}$ a 3 & $\mathbf{3}$ a 4 & $\mathbf{4}$ a 5 & $\mathbf{5}$ a 6 & $\mathbf{6}$ a 7 & $\mathbf{7}$ a 8 & $\mathbf{8}$ a 9 & $\mathbf{9}$ a 10 \\
\hline RMR 1 (LCBR-04) & 0,085 & 0,231 & 0,085 & 0,118 & 0,167 & 0,250 & 0,193 & 0,056 & - & - \\
RMR 2 (LCBR-12) & - & 0,510 & 0,164 & 0,104 & 0,179 & 0,014 & 0,881 & - & - & - \\
RMR 3 (LCBR-14) & - & 1,058 & 0,823 & 0,470 & 1,528 & 0,940 & 0,175 & 0,823 & 0,940 & 1,645 \\
RMR 4 (Estación Vía Tufiño-Maldonado) & 0,596 & 4,410 & 0,238 & 1,431 & 2,386 & 0,716 & & - & - & - \\
RMR 5 (Estación Aguas Hediondas) & 2,135 & 3,382 & 2,492 & 3,382 & 3,560 & 3,560 & 0,712 & - & - & - \\
\hline
\end{tabular}


Con los datos de la TABLA 4 se estimó el valor RQD (Rock Quality Designation) para cada afloramiento mediante la FÓRMULA 1, la cual implica descartar en las sumas separaciones entre discontinuidades que son menores a $0,1 \mathrm{~m}$.

$$
R Q D=\frac{\sum \text { longitud en la sección }>0,1 m}{\text { Longitud total sección }} * 100
$$

FÓRMULA 1. Criterio para la determinación del RQD.

En la TABLA 5 se listan los valores RQD obtenidos.

TABLA 5. Datos obtenidos mediante la utilización de la FÓRMULA 1 para los 5 afloramientos. "Suma" se refiere a la sumatoria de los valores en cada fila de la TABLA 4, que representaran separaciones $>0,1 \mathrm{~m}$.

\begin{tabular}{cccc}
\hline Estación & Suma & Longitud de referencia (m) & RQD \\
\hline RMR 1 & 0,96 & 1,18 & 81,36 \\
RMR 2 & 1,84 & 2 & 92,00 \\
RMR 3 & 8,40 & 9,4 & 89,36 \\
RMR 4 & 9,78 & 9,9 & 98,79 \\
RMR 5 & 19,22 & 19,40 & 99,07 \\
\hline
\end{tabular}

Con los datos de RQD para cada estación, y siguiendo a Jerram y Petford (2011), se procedió a calcular el valor RMR usando la TABLA 3 (ver sección METODOLOGÍA). Para el valor de resistencia de las cinco localidades se tomó un valor uniforme de $150 \mathrm{MPa}$. Para la valoración por separación entre discontinuidades, se usó la mediana de los valores en cada fila de la TABLA 4, luego de descartar separaciones menores a $0,1 \mathrm{~m}$. Los datos obtenidos se resumen en la TABLA 6.

TABLA 6. Valores de RMR para los 5 afloramientos estudiados.

\begin{tabular}{cc}
\hline Estación & Valor RMR \\
\hline RMR 1 & 82 \\
RMR 2 & 85 \\
RMR 3 & 79 \\
RMR 4 & 77 \\
RMR 5 & 92 \\
\hline
\end{tabular}

A continuación, se hallaron los esfuerzos compresivos usando el criterio Hoek-Brown, para ello se tuvieron en cuenta las FÓRMULAS 2 y 3 :

$$
\sigma=\left(s \sigma_{c}^{2}\right)^{1 / 2}
$$

FÓRMULA 2. Ecuación para el esfuerzo compresivo (Jerram y Petford, 2011). $\sigma_{c}$ es la resistencia compresiva de la masa rocosa (en este caso tomada constante e igual a $150 \mathrm{MPa}$ para los cinco sitios).

La constante s, en la FÓRMULA 2, se calcula mediante la FÓRMULA 3:

$$
s=\exp [\mathrm{RMR}-100) / 9]
$$

FÓRMULA 3. Constante $s$ de la FÓRMULA 2 (Jerram y Petford, 2011). "exp" significa elevar el número $e$ a una potencia equivalente a $(R M R-100) / 9$.

Los valores obtenidos de esfuerzo compresivo para cada RMR se presentan en la TABLA 7.

TABLA 7. Valores del esfuerzo compresivo en los 5 afloramientos a los cuales se aplicó el método RMR.

\begin{tabular}{ccc}
\hline Estación & $\boldsymbol{s}$ & $\boldsymbol{\sigma}(\mathbf{M P a})$ \\
\hline RMR 1 & 0,135 & 55,11 \\
RMR 2 & 0,188 & 65,04 \\
RMR 3 & 0,097 & 46,72 \\
RMR 4 & 0,078 & 41,89 \\
RMR 5 & 0,411 & 96,16 \\
\hline
\end{tabular}

